OPEN ACCESS

Edited by: Douglas Taren,

University of Arizona, USA

Reviewed by:

Erin Gaffney-Stomberg,

United States Army Research Institute of Environmental Medicine,

Lisa M Renzi,

USA

The University of Georgia, USA

*Correspondence: Michael Rychlik

michael.rychlik@tum.de

tPresent address:

Michael Netzel,

Centre for Nutrition and Food Sciences, Queensland Alliance for Agriculture and Food Innovation, The University of Queensland, St.

Lucia, QLD, Australia; Gabriele Netzel,

Centre for Animal Science,

Queensland Alliance for Agriculture and Food Innovation,

The University of Queensland,

St. Lucia, QLD, Australia

Specialty section:

This article was submitted to Nutrition Methodology, a section of the journal

Frontiers in Nutrition

Received: 11 January 2016

Accepted: 26 March 2016

Published: 08 April 2016

Citation:

Mönch S, Netzel M, Netzel G, Ott U,

Frank T and Rychlik M (2016) Pilot

Study on Folate Bioavailability from a Camembert Cheese Reveals

Contradictory Findings to Recent

Results from a Human

Short-term Study.

Front. Nutr. 3:9.

doi: 10.3389/fnut.2016.00009

\section{Pilot Study on Folate Bioavailability from a Camembert Cheese Reveals Contradictory Findings to Recent Results from a Human Short-term Study}

\author{
Sabine Mönch ${ }^{1}$, Michael Netzel2t, Gabriele Netzel2t, Undine Ott ${ }^{3}$, Thomas Frank ${ }^{4}$ and \\ Michael Rychlik ${ }^{5 *}$ \\ ${ }^{1}$ Lehrstuhl für Lebensmittelchemie, Technische Universität München, Freising, Germany, ${ }^{2}$ Department of Human Nutrition, \\ Institute of Nutrition, Friedrich Schiller Universität Jena, Jena, Germany, ${ }^{3}$ Kuratorium für Dialyse und Nierentransplantation \\ e.V., Jena, Germany, ${ }^{4}$ Private Consultant, Bad Soden, Germany, ${ }^{5}$ Chair of Analytical Food Chemistry, Technische Universität \\ München, Freising, Germany
}

Different dietary sources of folate have differing bioavailabilities, which may affect their nutritional "value." In order to examine if these differences also occur within the same food products, a short-term human pilot study was undertaken as a follow-up study to a previously published human trial to evaluate the relative native folate bioavailabilities from low-fat Camembert cheese compared to pteroylmonoglutamic acid as the reference dose. Two healthy human subjects received the test foods in a randomized cross-over design separated by a 14-day equilibrium phase. Folate body pools were saturated with a pteroylmonoglutamic acid supplement before the first testing and between the testings. Folates in test foods and blood plasma were analyzed by stable isotope dilution assays. The biokinetic parameters $C_{\max }, t_{\max }$, and area under the curve (AUC) were determined in plasma within the interval of $0-12 \mathrm{~h}$. When comparing the ratio estimates of $A \cup C$ and $C_{\max }$ for the different Camembert cheeses, a higher bioavailability was found for the low-fat Camembert assessed in the present study ( $\geq 64 \%$ ) compared to a different brand in our previous investigation (8.8\%). It is suggested that these differences may arise from the different folate distribution in the soft dough and firm rind as well as differing individual folate vitamer proportions. The results clearly underline the importance of the food matrix, even within the same type of food product, in terms of folate bioavailability. Moreover, our findings add to the increasing number of studies questioning the general assumption of 50\% bioavailability as the rationale behind the definition of folate equivalents. However, more research is needed to better understand the interactions between individual folate vitamers and other food components and the potential impact on folate bioavailability and metabolism.

Keywords: bioavailability, Camembert cheese, humans, folates, stable isotope dilution assay 


\section{INTRODUCTION}

Folates are "key players" in the one-carbon metabolism pathways and thus are involved in DNA synthesis, amino acid metabolism, and methylations (1). However, mean intake of folate in many countries is considered to be below the dietary recommendations for humans. Low dietary intake of folate is linked with the risk of neural tube defects (2) and is suspected to be associated with the development of certain forms of cancer (3), Alzheimer's disease (4), and cardiovascular disease (5). Obeid and colleagues concluded in a recently published study that there is an epidemic of folic acid-preventable spina bifida and anencephaly in Europe and that mandatory fortification would improve public health in Germany and other European countries (6). Therefore, many countries in the European Union favor the consumption of foods endogenously high in folates or increasing endogenous folate content in foods. However, apart from folate content alone, bioavailability appears to be the challenge if folate supply from foods is intended to be increased. The current dietary recommendations are based on the findings of Sauberlich et al. (7), who determined in a long-term human study a $50 \%$ bioavailability of native folates from foods relative to pteroylmonoglutamic acid. This value has since been questioned as subsequent studies revealed bioavailabilities of folates, e.g., from spinach of $89-113 \%$ (8), from citrus fruits and vegetables of $98 \%$ (9) relative to pteroylmonoglutamic acid, or from broccoli and strawberries of $99-120 \%$ relative to $5-\mathrm{CH}_{3}-\mathrm{H}_{4}$ folate (10). This prompted us to conduct a recently published human study on folate bioavailability by using stable isotope dilution assays for analysis of plasma folate and an area under the curve (AUC) approach (11). A surprisingly high inter-individual variation in folate bioavailability and also highly different bioavailabilities of the test foods ranging from $8.8 \%$ for Camembert cheese to $73 \%$ for spinach relative to pteroylmonoglutamic acid could be observed (12). However, we did not investigate the potential variation in folate bioavailability within the same test food, e.g., Camembert cheese. Therefore, the aim of the present pilot study was to compare the oral bioavailability and biokinetic data between pure compound of pteroylmonoglutamic acid as the reference and native folate from a low-fat type Camembert cheese of a brand different to that used in the aforementioned human study (12). The bioavailability data of the cheese, which is a popular and significant dietary source of folate in Germany (13), were obtained from analyses of $5-\mathrm{CH}_{3}-\mathrm{H}_{4}$ folate in plasma following oral administration.

\section{MATERIALS AND METHODS}

\section{Chemicals}

The following chemicals were obtained commercially from the sources given in parentheses: rat serum (Biozol, Eching, Germany), chicken pancreas (Difco, Sparks, MD, USA), acetic acid, acetonitrile, sodium phosphate dibasic dihydrate, formic acid, hexane, methanol, potassium phosphate monobasic, sodium hydroxide, sodium chloride (Merck, Darmstadt, Germany), alpha-amylase, ammonium formate, ascorbic acid, pteroylmonoglutamic acid, 4-morpholineethanesulfonic acid
(MES), 2-mercaptoethanol, protease type XIV, sodium acetate (Sigma, Deisenhofen, Germany), (6S)-tetrahydrofolic acid, calcium (6S)-5-methyltetrahydrofolate, 10-formylfolic acid, and (6S)-5-formyltetrahydrofolic acid (Schircks, Jona, Switzerland). All chemicals were at least of analytical-reagent grade. $\left[{ }^{2} \mathrm{H}_{4}\right]-$ 5-methyltetrahydrofolic acid, $\left[{ }^{2} \mathrm{H}_{4}\right]-5$-formyltetrahydrofolic acid, $\left[{ }^{2} \mathrm{H}_{4}\right]$-tetrahydrofolic acid, $\left[{ }^{2} \mathrm{H}_{4}\right]-10$-formylfolic acid, and $\left[{ }^{2} \mathrm{H}_{4}\right]$-pteroylmonoglutamic acid were synthesized as previously reported (14).

\section{Test Foods}

A low-fat Camembert cheese (16 g fat/100 g) was purchased at a local supermarket in the city of Munich, Germany. The pteroylmonoglutamic acid solution was prepared by suspending pteroylmonoglutamic acid $(2.0 \mathrm{mg})$ in tap water, which was then alkalized with dilute sodium hydroxide until all solids were dissolved and then adjusted to $\mathrm{pH} 7$ with dilute hydrochloric acid followed by adjustment to volume $(1 \mathrm{~L})$ with tap water. The Camembert cheese under study was assessed in two different ways: (a) whole cheese samples were frozen in liquid nitrogen and homogenized in entirety and (b) cheese samples were segmented into rind and dough and analyzed separately by stable isotope dilution assays as previously described (15). Quality control was performed by assessing recovery, precision, linearity, LOD, limit of quantification (LOQ), and the analysis of dried, mixed vegetables as certified reference material (16).

\section{Plasma}

Plasma samples were analyzed by stable isotope dilution assays using phenyl SPE cleanup as detailed by Mönch et al. (17). Briefly, aliquots of plasma $(400 \mu \mathrm{L})$ were spiked with $\left[{ }^{2} \mathrm{H}_{4}\right]-5$ methyltetrahydrofolic acid (5 ng in MES buffer) and then overlaid with ammonium formate buffer $(600 \mu \mathrm{L})$ and equilibrated for $30 \mathrm{~min}$ at room temperature and subjected to cleanup on phenyl SPE cartridges (Discovery DSC-ph, $100 \mathrm{mg}, 1 \mathrm{~mL}$, Varian, Darmstadt, Germany). Folates were eluted from SPE columns with $0.5 \mathrm{~mL}$ of a mixture of aqueous sodium chloride (5\%) and sodium acetate (100 mmol/L; $1 \%$ ascorbic acid). The lower limit of quantification (LLOQ) was $0.37 \mathrm{nmol} / \mathrm{L}$.

\section{Pilot Study and Ethical Permission}

Two healthy, non-smoking Caucasian female subjects participated in the pilot study with a mean $( \pm$ SD) age of $25.5( \pm 2.1)$ years and a mean $\left( \pm\right.$ SD) body mass index of $20.9( \pm 2.1) \mathrm{kg} / \mathrm{m}^{2}$. Ethical permission was obtained by the Ethics Committee of the Friedrich Schiller University Jena, Faculty of Medicine (code 1415-09/04). The study was carried out in accordance with the recommendations of the Ethics Committee given above with written informed consent from all subjects. All subjects gave written informed consent in accordance with the Declaration of Helsinki. To improve the uniformity among the two subjects and subsequently the precision of bioavailability estimates, a pteroylmonoglutamic acid supplement $(800 \mu \mathrm{g} / \mathrm{day}=1.8 \mu \mathrm{mol} /$ day) was given for 14 days before the first testing and between the testings and was discontinued 2 days prior to the start of 
the study (12). The study had a randomized cross-over design, and each subject had the following experimental treatments separated by a 14-day equilibrium phase: 448-nmol total folates via Camembert cheese (200 g) and 453-nmol pteroylmonoglutamic acid via orally administered pteroylmonoglutamic acid solution $(100 \mathrm{~mL})$ serving as reference treatment. After an overnight fast, volunteers took the Camembert cheese or drank the pteroylmonoglutamic acid solution, respectively, together with one slice of toast bread. During the experimental treatment periods $(24 \mathrm{~h})$, the consumption of water was allowed ad libitum, and two further standardized and virtually folatefree study meals consisting of wheat bread (nine slices or $500 \mathrm{~g}$ ), butter (100 g), and honey (250 g) were offered for lunch and dinner. Venous blood samples $(9 \mathrm{~mL})$ were drawn in EDTAcoated tubes (Sarstedt, Nuernbrecht, Germany) predose, as well as $1,2,3,4,5,6,8,10,12$, and $24 \mathrm{~h}$ after the administration of Camembert cheese or reference solution. Blood was centrifuged $\left(10 \mathrm{~min} / 2000 \times \mathrm{g} / 4^{\circ} \mathrm{C}\right)$ to separate plasma from red blood cells. Plasma was stored frozen at $-24^{\circ} \mathrm{C}$ until further preparation and analysis.

\section{Biokinetic Calculations}

Plasma 5- $\mathrm{CH}_{3}-\mathrm{H}_{4}$ folate was evaluated. In the first step, the individual predose $(t=0 \mathrm{~h}) 5-\mathrm{CH}_{3}-\mathrm{H}_{4}$ folate plasma concentrations were subtracted from all subsequent values. Negative concentrations that might result from this procedure were discarded. The predose-corrected concentrations were subjected to a standard non-compartmental analysis in order to derive $C_{\max }$ (observed maximum plasma concentration), $t_{\max }$ (time of $C_{\max }$ ), and AUC (area under the plasma concentration-time curve) (18). The calculation of the AUC was done by linear trapezoidal rule and was limited within the interval between 0 and $12 \mathrm{~h}$ after dose, because after $12 \mathrm{~h}$, a somewhat unexpected and marked increase up to $24 \mathrm{~h}$ after dose occurred (see Figure 1). Concentrations below the LLOQ were treated as 0 .

\section{RESULTS}

For determining the exact folate dose, we analyzed the Camembert cheese for individual folate vitamers and found considerably lower total folate content and a rather different folate profile compared to the Camembert cheese (different brand) assessed in our previous study (12). Whereas the latter contained as much as $647 \mathrm{nmol} / 100 \mathrm{~g}$ total folate and its major folate vitamer was tetrahydrofolate, the total folate content of the Camembert cheese in the present study was only $224 \mathrm{nmol} / 100 \mathrm{~g}$, and its major vitamer was 5 -formyltetrahydrofolate (Table 1 ). The time course of the $5-\mathrm{CH}_{3}-\mathrm{H}_{4}$ folate (non-predose-corrected) concentrations in plasma is shown in Figure 1. After intake of Camembert cheese, the concentrations increased up to $2-3 \mathrm{~h}$ after dose and decreased below the predose values to a local minimum at 6 and $8 \mathrm{~h}$ after dose. Thereafter, the concentrations increased continuously up to the next morning, i.e., $24 \mathrm{~h}$ after intake, well above the predose values. After intake of folic (pteroylmonoglutamic) acid solution,

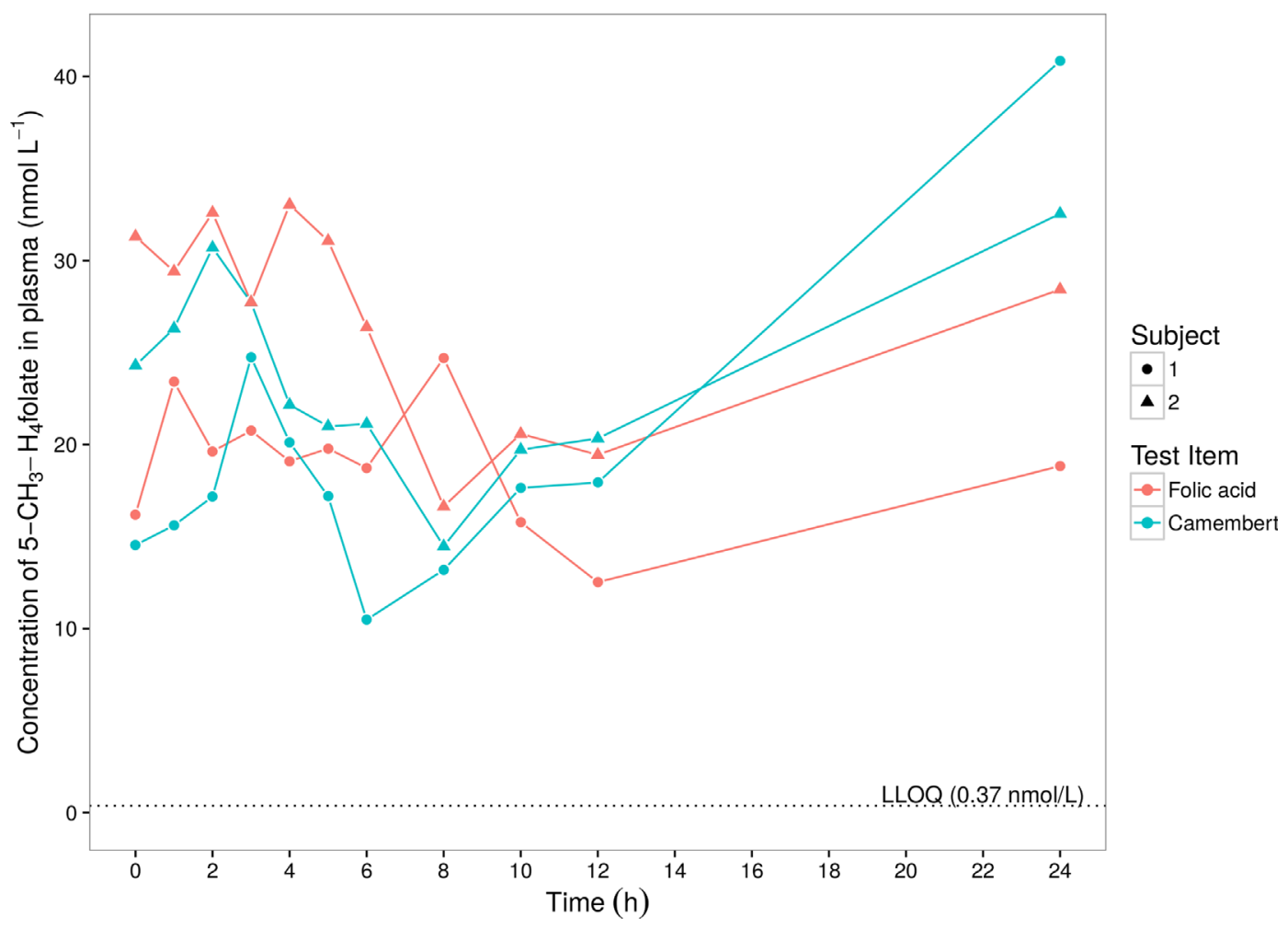

FIGURE 1 | 5-Methyltetrahydrofolate levels in plasma of two volunteers after intake of folic acid solution or Camembert cheese. 
TABLE 1 | Folate distribution and sum of all folate vitamers in the test foods, mean \pm SD $(n=3)$.

\begin{tabular}{|c|c|c|c|c|c|c|}
\hline Food & $\begin{array}{c}\text { Tetrahydrofolate } \\
(\mu \mathrm{g} / 100 \mathrm{~g})\end{array}$ & $\begin{array}{l}\text { 5-Methyl-tetrahydrofolate } \\
\qquad(\mu \mathrm{g} / 100 \mathrm{~g})\end{array}$ & $\begin{array}{c}\text { 5-Formyl-tetrahydrofolate } \\
(\mu \mathrm{g} / 100 \mathrm{~g})\end{array}$ & $\begin{array}{l}\text { 10-Formylfolate } \\
(\mu \mathrm{g} / 100 \mathrm{~g})\end{array}$ & $\begin{array}{l}\text { Pteroylmonoglutamic } \\
\text { acid }(\mu \mathrm{g} / 100 \mathrm{~g})\end{array}$ & $\begin{array}{l}\text { Sum of folates } \\
\text { (nmol/100 g) }\end{array}$ \\
\hline $\begin{array}{l}\text { Camembert cheese } \\
\text { (present study) }\end{array}$ & $17.7 \pm 1.8$ & $31.9 \pm 4.5$ & $38.6 \pm 0.9$ & $6.4 \pm 0.6$ & n.d. & $224 \pm 18$ \\
\hline Camembert cheese (12) & $144.7 \pm 12.9$ & $46.2 \pm 2.2$ & $54.5 \pm 4.1$ & $40.2 \pm 5.3$ & n.d. & $647 \pm 16$ \\
\hline
\end{tabular}

n.d., not detectable.

TABLE 2 | Summary table of baseline corrected $5-\mathrm{CH}_{3}-\mathrm{H}_{4}$ folate biokinetic parameter in plasma.

\begin{tabular}{|c|c|c|}
\hline Parameter $^{\mathrm{a}}$ & Camembert & Oral solution \\
\hline$C_{\max }(\mathrm{nmol} / \mathrm{L})$ & $17.3 \pm 12.8$ & $5.11 \pm 4.79$ \\
\hline$t_{\max }(\mathrm{h})$ & $24(24,24)$ & $6(4,8)$ \\
\hline $\mathrm{AUC}_{0-12}(\mathrm{nmol} \cdot \mathrm{h} / \mathrm{L})^{\mathrm{b}}$ & $45.9 \pm 5.96$ & 65.0 (n.c.) n.c. \\
\hline $\begin{array}{l}\text { Ratio estimate in \% of reference baseline } \\
\text { corrected and dose-normalized }\end{array}$ & $71 / 65$ & \\
\hline
\end{tabular}

Doses of the testings were 448 and $453 \mathrm{nmol}$ sum of folates via Camembert cheese and oral solution of pteroylmonoglutamic acid, respectively.

Tabulated values are arithmetic mean $\pm S D(C V \%)$ of $n=2$ subjects except for $t_{\max }$ where values are median (min, max); n.c., not calculated because AUC was not calculated in subject 2; reason: this subject had its last positive, pre-post-dose concentration difference at $4 \mathrm{~h}$ after dosing.

${ }^{a} C_{\max }$ and $t_{\max }$ were determined within the 0 - to 24- $h$ interval.

${ }^{b} A \cup C_{0-12}$ is the positive AUC within the interval $0-12 h$, i.e., concentrations falling below the individual predose values were discarded.

'Oral solution as reference, percentage based on the mean of $A \cup C_{0-12} /$ based on the subject with valid Camembert and oral solution AUC data.

the curves showed a fluctuating increase with maxima reached within the region between 2 and $8 \mathrm{~h}$ after dose. At 8 and $12 \mathrm{~h}$ after dose, concentrations reached a minimum which was below the predose values in both subjects, followed by a continuous increase up to the next morning. Due to sufficient reducing and methylation capacity in intestinal epithelium and the liver, no other folate vitamers than $5-\mathrm{CH}_{3}-\mathrm{H}_{4}$ folate were detectable in circulating plasma. The increase in plasma folate concentration at late sampling times after folate dosage was also observed in our previous study (12). The suppression of bile production and excretion under fasting conditions is most likely the reason for the observed increase (19). In order to exclude these obvious effects at the last sampling time of $24 \mathrm{~h}$, the kinetic evaluation was limited to the range of $0-12 \mathrm{~h}$. Table 2 summarizes the biokinetic parameters of predose-corrected $5-\mathrm{CH}_{3}-\mathrm{H}_{4}$ folate. The time to attain the maximum concentrations $\left(t_{\max }\right)$ was highly variable among treatments. The results were surprising as the low-fat Camembert in the present study showed a much higher folate bioavailability (65-71\%, c.f. Table 2) than the low-fat Camembert investigated in our previous study, when we found a mean bioavailability of $8.8 \%$ for all 24 volunteers (12). However, as both studies were conducted under virtually identical conditions and only a few weeks apart and the two volunteers of the present study also participated in the other one, a cross-study comparison [present pilot study vs. Ref. (12)] is possible. Both volunteers also revealed a tremendous lower folate bioavailability for the other Camembert as low as 9.2 and $16.4 \%$, respectively, relative to the reference dose of the folic acid solution.

\section{DISCUSSION}

The reason for this may be explained by the different folate distributions in the two cheeses. The Camembert with the lower bioavailability (12) contained most of its folates (80\%) in the rind, which is a more compact and firm matrix than the dough and may render the folates less accessible during gastrointestinal digestion. In contrast to this, in the present study, more than $60 \%$ of the folate vitamers could be found in the relatively soft dough matrix. Moreover, the major folate vitamer in the Camembert cheese with lower bioavailability was tetrahydrofolate (12), which is the least stable vitamer and therefore, particularly susceptible to degradation in the gastrointestinal environment (20).

The cross-study comparison [present pilot study vs. Ref. (12)] of the Camembert results of the two subjects, who participated in both studies, substantiated the different bioavailabilities on an intraindividual level (65-71 vs. 9-16\%), despite the few volunteers in the present investigation. Moreover, as both studies were run under virtually identical conditions, they indicated the Camembert cheeses (different folate profiles and matrix distribution) as the determining factors. Also, the low number of recruited subjects in the present study is not unusual for pilot studies investigating the bioavailability and metabolism of bioactive food components $(21,22)$ with reported number(s) as low as one (23). However, we still want to emphasize that our study is an exploratory and limited one as there is only for one volunteer a complete data set.

Nevertheless, our results underline the dependence of folate bioavailability on the specific food product/type ingested. The reasons for the differences of folate bioavailability are still unclear. Previously, we assumed that (a) different kinetics and bioavailabilities of the folate vitamers (24) and particularly of the polyglutamate forms, (b) presence of deconjugase inhibitors, and (c) entrapping of folates in the food matrix may account for these differences. Therefore, the general folate bioavailability from foods of $50 \%$ as the basis for the definition of folate equivalents must be seriously questioned, and its generality requires further investigation. Possible approaches are further testing of foods in human studies with less expensive designs, such as sampling of dried blood spots (25) or the application of in vitro digestion models, which can be used as a cost- and time-efficient high throughput "screening tool." The respective investigations are currently in progress.

\section{CONCLUSION}

Although on a pilot scale, the results of the present study clearly demonstrate that a food product (e.g., Camembert cheese) cannot be regarded as a homogenous dietary "standard" with a predictable folate bioavailability. Mandatory folic acid fortification as 
successfully implemented in many countries, including the USA and Canada (6), is therefore a very efficient strategy to overcome these shortcomings in folate bioavailability and subsequently bioactivity.

\section{AUTHOR CONTRIBUTIONS}

MN, GN, and UO carried out the human study. SM developed the folate assay and analyzed the blood samples. TF performed the biokinetic calculations. The study was designed by MN, GN, and MR. The manuscript was written by MR, MN, GN, TF, and SM.

\section{REFERENCES}

1. Selhub J. Folate. J Nutr Health Aging (2002) 6:39-42.

2. Czeizel AF, Dudas J. Prevention of the first occurrence of neural-tube defects by periconceptional vitamin supplementation. New Engl J Med (1992) 327:1832-5. doi:10.1056/NEJM199212243272602

3. Caudill M. The role of folate in reducing chronic and developmental disease risk: an overview. J Food Sci (2003) 69:SNQ55-67. doi:10.1111/j. 1365-2621.2004.tb17887.x

4. Snowdon DA, Tully CL, Smith CD, Riley KP, Markesbery WR. Serum folate and the severity of atrophy of the neocortex in Alzheimer disease: findings from the Nun study. Am J Clin Nutr (2000) 71:993-8.

5. Robinson K. Homocystein, B vitamins, and risk of cardiovascular disease. Heart (2000) 83:127-30. doi:10.1136/heart.83.2.127

6. Obeid R, Pietrzik K, Oakley GP Jr, Kancherla V, Holzgreve W, Wieser S. Preventable spina bifida and anencephaly in Europe. Birth Def Res A (2015) 103:763-71. doi:10.1002/bdra.23400

7. Sauberlich HE, Kretsch MJ, Skala JH, Johnson HL, Taylor PC. Folate requirement and metabolism in nonpregnant women. Am J Clin Nutr (1987) 46:1016-28.

8. Prinz-Langenohl R, Bronstrup A, Thorand B, Hages M, Pietrzik K. Availability of food folate in humans. J Nutr (1999) 129:913-6.

9. Brouwer IA, Van Dusseldorp M, West CE, Meyboom S, Thomas CMG, Duran $\mathrm{M}$, et al. Dietary folate from vegetables and citrus fruit decreases plasma homocysteine concentrations in humans in a dietary controlled trial. J Nutr (1999) 129:1135-9.

10. Witthöft CM, Strålsjö L, Berglund G, Lundin E. A human model to determine folate bioavailability from food: a pilot study for evaluation. Scand J Nutr (2003) 47:6-18. doi:10.1080/11026480310000383

11. Rychlik M, Netzel M, Pfannebecker I, Frank T, Bitsch I. Application of stable isotope dilution assays based on liquid chromatography-tandem mass spectrometry for the assessment of folate bioavailability. J Chromatogr B (2003) 792:167-76. doi:10.1016/S1570-0232(03)00254-X

12. Mönch S, Netzel M, Netzel G, Ott U, Frank T, Rychlik M. Folate bioavailability from foods rich in folates assessed in a short term human study using stable isotope dilution assays. Food Func (2015) 6:242-8. doi:10.1039/ c4fo00658e

13. Rychlik M. Revised folate data in foods determined by stable isotope dilution assays. J Food Comp Anal (2004) 17:475-83. doi:10.1016/j.jfca.2004.03.017

14. Freisleben A, Schieberle P, Rychlik M. Syntheses of labeled vitamers of folic acid to be used as internal standards in stable isotope dilution assays. J Agric Food Chem (2002) 50:4760-8. doi:10.1021/jf025571k

\section{ACKNOWLEDGMENTS}

The authors thank Dr. Mary Fletcher from the Queensland Alliance for Agriculture and Food Innovation (QAAFI), the University of Queensland, for the critical review of the manuscript.

\section{FUNDING}

This study was supported by a grant from the Deutsche Forschungsgemeinschaft (RY 19/7-1; NE 1188/1-1).

15. Mönch S, Rychlik M. Improved folate extraction and tracing deconjugation efficiency by dual label isotope dilution assays in foods. J Agric Food Chem (2012) 60:1363-72. doi:10.1021/jf203670g

16. Ringling C, Rychlik M. Analysis of seven folates in food by LC-MS/MS to improve accuracy of total folate data. Eur Food Res Technol (2013) 236:17-28. doi:10.1007/s00217-012-1849-x

17. Mönch S, Netzel M, Netzel G, Rychlik M. Quantitation of folates and their catabolites in blood plasma, erythrocytes, and urine by stable isotope dilution assays. Anal Biochem (2010) 398:150-60. doi:10.1016/j. ab.2009.11.007

18. Cawello W. Parameters for Compartment-Free Pharmacokinetics. Aachen: Shaker (1999). p. 20-5.

19. Pietrzik K, Hages M, Remer T. Methodological aspects in vitamin bioavailability testing. J Micronutr Anal (1990) 7:207-22.

20. Oehrvik V, Oehrvik H, Tallkvist J, Witthoeft CM. Folates in bread: retention during bread-making and in vitro bioaccessibility. Eur J Nutr (2010) 49:365-72. doi:10.1007/s00394-010-0094-y

21. Kay CD, Mazza G, Holub BJ, Wang J. Anthocyanin metabolites in human urine and serum. Br J Nutr (2004) 91:933-42. doi:10.1079/BJN20041126

22. Kay CD, Mazza G, Holub BJ. Anthocyanins exist in the circulation primarily as metabolites in adult men. J Nutr (2005) 135:2582-8.

23. Cao GH, Prior RL. Anthocyanins are detected in human plasma after oral administration of an elderberry extract. Clin Chem (1999) 45:574-6.

24. Oehrvik V, Buettner B, Rychlik M, Lundin E, Witthoeft CM. Folate bioavailability from breads and a meal assessed with a human stable-isotope area under the curve and ileostomy model. Am J Clin Nutr (2010) 92:532-8. doi:10.3945/ajcn.2009.29031

25. Kopp M, Rychlik M. Quantitation of 5-methyltetrahydrofolic acid in dried blood spots and dried plasma spots by stable isotope dilution assays. PLoS One (2015) 10(11):e0143639. doi:10.1371/journal.pone.0143639

Conflict of Interest Statement: The authors declare that the research was conducted in the absence of any commercial or financial relationships that could be construed as a potential conflict of interest.

Copyright (C) 2016 Mönch, Netzel, Netzel, Ott, Frank and Rychlik. This is an open-access article distributed under the terms of the Creative Commons Attribution License (CC BY). The use, distribution or reproduction in other forums is permitted, provided the original author(s) or licensor are credited and that the original publication in this journal is cited, in accordance with accepted academic practice. No use, distribution or reproduction is permitted which does not comply with these terms. 